\title{
Preparation of High Purity Xylenol Orange and Isolation of a New Metallochromic Dye by Cation Exchange Column Chromatography on SP-Sephadex
}

\author{
Hiroaki Nakayama, Satoshi Tachiyashiki and Minoru Ishi \\ Laboratory of Chemistry, Kagawa Nutrition College, Sakado, Saitama 350-02, Japan
}

\begin{abstract}
Keywords Xylenol Orange, synthetic condition, SP-Sephadex, column chromatography, Glycine Imminodiacetic Acid Cresol Red
\end{abstract}

Xylenol Orange (XO), 3,3'-bis[ $N, N$-bis(carboxymethyl)aminomethyl]-o-cresolsulfonphthalein, has been known as the most useful sulfonphthalein complexone metallochromic indicator. ${ }^{1,2}$ It has been extensively studied in its metal complex formation equilibria. ${ }^{3,4}$ To obtain pure XO from its crude form, however, is not easy. ${ }^{5,6}$ For example, even after being purified by cellulose column chromatography, there still remains several $\%$ of an unidentified colored impurity $(\beta-\mathrm{XO}){ }^{?}$

The present paper describes the synthetic condition to obtain XO of high purity, or to minimize the formation of byproducts such as Semi-XO (SXO) and $\beta-X O$, in place of separating them. It also describes the isolation of byproducts having a very analogous structure with $\mathrm{XO}$, i.e., $\beta$-XO and a new metallochromic dye, Glycine Imminodiacetic acid Cresol Red (GICR), $3-[N$-(carboxymethyl)aminomethyl $]-3^{\prime}-\left[N^{\prime}, N^{\prime}\right.$-bis(carboxymethyl)aminomethyl]-o-cresolsulfonephthalein, by using cation exchange column chromatography on SP-Sephadex under an acidic condition which was developed for analyzing synthetic reaction products. The chromatography was so efficient in separating many colored materials within a short time that it was quite suitable for a ready and speedy purification of commercial sulfonephthalein dyes.

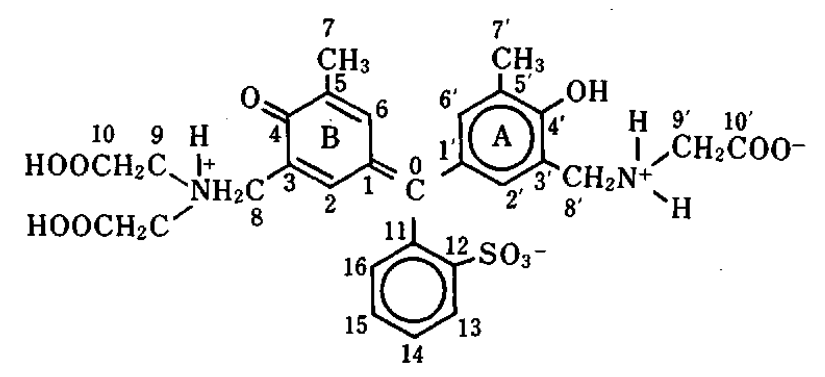

Fig. 1 Structure of GICR and the numbering of carbons.

\section{Experimental}

All the reagents and procedures were the same as those described previously ${ }^{8}$, except for the measurement of the ${ }^{13} \mathrm{C}-\mathrm{NMR}$ spectra, which was performed in $\mathrm{D}_{2} \mathrm{O}$ solutions at various $\mathrm{pD}$ with a JEOL JNM-FX100/PFT-100 spectrometer. Dioxane $(\delta=67.4)$ was used as an internal reference. ${ }^{3}$

\section{Synthesis of Xylenol Orange}

A mixture of Cresol Red (CR; $1.91 \mathrm{~g}, 5 \mathrm{mmol}$ ), iminodiacetic acid (IDA; $2.66 \mathrm{~g}, 20 \mathrm{mmol}$ ), anhydrous sodium acetate $(5.10 \mathrm{~g}, 62 \mathrm{mmol})$ and acetic acid $(50 \mathrm{ml})$ was kept at $55^{\circ} \mathrm{C}$, and $2.5 \mathrm{ml}$ of aqueous $37 \%$ formaldehyde ( $31 \mathrm{mmol})$ were added to it. The mixture was kept at $55^{\circ} \mathrm{C}$ under stirring for $2.5 \mathrm{~h}$, and then cooled in an ice bath and left overnight at room temperature. A supernatant of the mixture was used for further treatment.

\section{Column chromatography on SP-Sephadex}

Synthetic solutions in acetic acid $(0.5 \mathrm{ml})$ were developed on $23 \mathrm{~mm}$ i.d. $\times 220 \mathrm{~mm}$ or $90 \mathrm{~mm} \mathrm{H}$-form SP-Sephadex columns with $50 \mathrm{mM} \mathrm{HCl}$ for product analysis. ${ }^{9}$ For preparative purpose the following procedure was carried out. To a synthetic mixture diethylether was added in order to precipitate crude XO. ${ }^{8}$ The obtained precipitate was dissolved in 11 of water; the mixture was then poured into a $28 \mathrm{~mm}$ i.d. $\times 22 \mathrm{~mm} \mathrm{Cl-form} \mathrm{DEAE-Sephadex} \mathrm{column,} \mathrm{washed}$ with water and eluted with $100 \mathrm{mM} \mathrm{HCl}$. The effluent was dried in vacuo. The residure was dissolved in a small amount of $50 \mathrm{mM} \mathrm{HCl}$ and the mixture developed on a $23 \mathrm{~mm}$ i.d. $\times 220 \mathrm{~mm}$ SP-Sephadex column with $50 \mathrm{mM} \mathrm{HCl}$.

Glycine Imminodiacetic Acid Cresol Red (GICR) and $\beta-X O$

GICR was collected from the effluent of preparative 
chromatography of synthesized XO on SP-Sephadex. The effluent was diluted with water ten times, and was then poured into a $22 \mathrm{~mm}$ i.d. $\times 30 \mathrm{~mm}$ DEAE-Sephadex column. The column was washed with $60 \mathrm{ml}$ of water, developed with $50 \mathrm{mM} \mathrm{NaCl}$ and then with $100 \mathrm{mM}$ $\mathrm{NaCl}$. The fraction of $\mathrm{GICR}^{9}$ was then diluted with water, adsorbed to DEAE-Sephadex, and eluted with $100 \mathrm{mM} \mathrm{HCl}$. The effluent was filtered and dried in vacuo. ${ }^{13} \mathrm{C}-\mathrm{NMR}\left[\mathrm{D}_{2} \mathrm{O}, \mathrm{pD} 1.6\right]$ (see Fig. 1): $\delta$ 173.8, $173.4\left(\mathrm{C}-4,4^{\prime}\right), 169.0\left(\mathrm{C}-10,10^{\prime}\right), 166.0(\mathrm{C}-0), 142.7$ (C-12), 140.9 (C-6, 6'), 139.2 (C-2, 2'), $137.3(\mathrm{C}-11)$, 132.5 (C-15), 131.6 (C-14), 131.3 (C-16), 131.1 (C-5, $\left.5^{\prime}\right), 130.5\left(\mathrm{C}-1,1^{\prime}\right), 128.9$ (C-13), 123.3, 120.7 (C-3, 3'), 56.0 (C-8), 55.2 (C-9), $42.5\left(\mathrm{C}-8^{\prime}\right), 47.9\left(\mathrm{C}-9^{\prime}\right), 16.6$ $\left(\mathrm{C}-7,7^{\prime}\right) \mathrm{ppm}$.

$\beta$-XO was collected ${ }^{9}$ from the effluent of $\mathrm{SP}-$ Sephadex chromatography of crude XO synthesized under Korbl's conditions. ${ }^{1,5}$ It was then purified using the same procedure as described for GICR. $\beta$-XO was eluted in front of GICR in the aforementioned DEAE chromatography. ${ }^{13} \mathrm{C}$ NMR $\left[\mathrm{D}_{2} \mathrm{O}, \mathrm{pD}\right.$ 1.6]: $\delta 210.9$ (C-17), 173.3, $172.2\left(\mathrm{C}-4,4^{\prime}\right), 169.7,169.0\left(\mathrm{C}-10,10^{\prime}\right)$, 166.0 (C-0), $142.6(\mathrm{C}-12), 140.9,139.8\left(\mathrm{C}-6,6^{\prime}\right), 139.2$, 138.8 (C-2, 2'), 137.4 (C-11), 132.5 (C-15), 131.7 (C14), 131.3 (C-16), 131.1 (C-5, 5'), 130.6, 130.5 (C-1, $\left.\mathrm{I}^{\prime}\right), 128.8$ (C-13), 123.3, $120.7\left(\mathrm{C}-3,3^{\prime}\right), 56.1$ (C-8), $53.3(\mathrm{C}-9), 47.6\left(\mathrm{C}-8^{\prime}\right), 47.9\left(\mathrm{C}-9^{\prime}\right), 46.4\left(\mathrm{C}-7,7^{\prime}\right) \mathrm{ppm}$.

\section{Results and Discussion}

\section{Synthetic condition to obtain XO of high purity}

Using SP-Sephadex column chromatography for product analysis, synthetic conditions of XO were investigated. The best one is described in the experimental section. Compared to conventional method ${ }^{1,5}$, the reaction period was shorter $(2.5 \mathrm{~h}$ compared to $10 \mathrm{~h})$, the reaction temperature lower $\left(55^{\circ} \mathrm{C}\right.$ compared to $65^{\circ} \mathrm{C}$ ), and had a two-fold higher concentrations of IDA, sodium acetate, and formaldehyde. The synthetic yield was improved from $80 \%$ to $98 \%$ and most of the byproducts decreased to undetectable amounts with very little amounts of SXO (1.2\%) and GICR $(0.8 \%)$.

\section{Byproducts of XO synthesis; new metallochromic dyes}

When the synthetic solution obtained under the present synthetic condition was chromatographed on a SP-Sephadex column, several minor colored bands appeared in addition to the two main bands of $\mathrm{XO}$ and SXO (Fig. 2). In order to find new types of complexone dyes among the byproducts, the properties of two kinds of the main byproduct dyes were investigated.

(1) Glycine Imminodiacetic Acid Cresol Red (GICR).

The dye of a yellow band next to the XO band in the elution curve (Fig. 2) showed a color change to violet $\left(\lambda_{\max }=570 \mathrm{~nm}\right)$ upon adding. $\mathrm{Cu}$ "l at $\mathrm{pH}$ 5. The ratio of maximum absorption of the $\mathrm{Cu}^{\mathrm{Il}}$ complex at $570 \mathrm{~nm}$ to that of free dye at $433 \mathrm{~nm}$ was 2.0. The color change

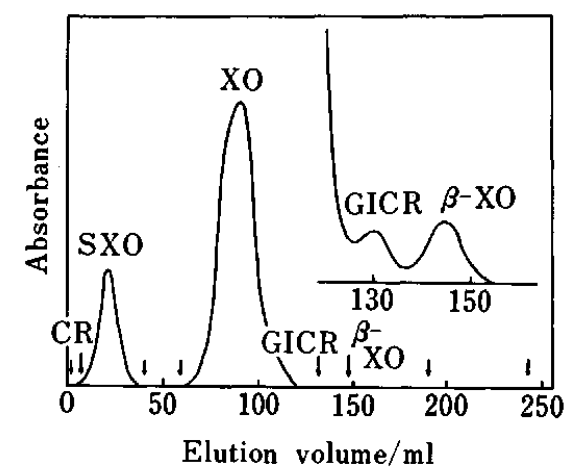

Fig. 2 Chromatogram of a synthetic solution of XO from an SP-Sephadex cation exchange column: eluent, $50 \mathrm{mM} \mathrm{HCl}$. Arrows indicate yellow bands of unidentified materials.

was similar to that observed for Glycine CR and SemiGCR. The dye changed color to reddish brown with a large excess of $\mathrm{Fe}^{\mathrm{III}}$ in $50 \mathrm{mM} \mathrm{HCl}$. The absorption spectrum of the solution had a maximum at $488 \mathrm{~nm}$ and two shoulders at 550 and $600 \mathrm{~nm}$. The shoulder at $550 \mathrm{~nm}$ corresponded to the absorption maximum $\left(\lambda_{\max }\right)$ of the $\mathrm{Fe}^{\mathrm{III}}-\mathrm{SXO}$ complex $(548 \mathrm{~nm})$. Thus, the dye was suggested to have both IDA and glycine moieties. To confirm this assignment, a synthetic reaction was performed by adding $2 \mathrm{mmol}$ of glycine to the reactants of the present XO synthesis $(5 \mathrm{mmol} C R$ and $20 \mathrm{mmol}$ IDA). The yield of the dye increased drastically from $0.8 \%$ to $17 \%$, indicating that it is a cross Mannich condensation product of glycine and IDA with CR. The glycine may have been produced by the hydrolysis of IDA.

The ${ }^{13} \mathrm{C}-\mathrm{NMR}$ spectra of the dye was measured in $\mathrm{D}_{2} \mathrm{O}$ at various $\mathrm{pD}$ in order to confirm its structure (for the NMR data, see experimental section). It was quite similar to that of $\mathrm{XO}^{3}$, except that some of the signals split into two, depending on pD; also, it had two more signals at 42.5 and $47.9 \mathrm{ppm}$ (values at $\mathrm{pD} 1.6$ ). The two signals can be assigned to those of aminomethylene (C-8', see Fig. 1) and carboxymethylene (C-9') carbons of glycine moiety (the signals of IDA moiety were at $56.0(\mathrm{C}-8)$ and $55.2(\mathrm{C}-9) \mathrm{ppm}$ ). The splitting of some signals reflected the inequivalence of A- and B-rings (Fig. 1) caused by cross Mannich condensation. Thus, the NMR results also indicated that the byproduct is GICR.

(2) $\beta-X O$. The dye of a yellow band next to the GICR band in the elution curve was produced when XO was synthesized under Korbl's conditions with a yield of several percent. The yield increased for a longer reaction time and/or higher temperature. ${ }^{7}$ The unidentified dye was named $\beta$-XO by Yamada et al., since it had almost an equivalent molecular formula to $\mathrm{XO}$, though different from XO regarding the color of the $\mathrm{Fe}^{\prime \prime \prime}$ complex. ${ }^{7}$ Its spectrum with large excess of $\mathrm{Fe}^{111}$ in $50 \mathrm{mM} \mathrm{HCl}$ showed an absorption maximum at $479 \mathrm{~nm}$ and a shoulder at $550 \mathrm{~nm}$, the latter corre- 
sponding to $\lambda_{\max }(548 \mathrm{~nm})$ of $\mathrm{Fe}^{\mathrm{III}}-\mathrm{SXO}$, suggesting that $\beta$-XO has only one IDA moiety. The color of $\beta-X O$ did not change much with a large excess of $\mathrm{Cu}^{\mathrm{Il}}$ at pH 4.8.

The ${ }^{13} \mathrm{C}-\mathrm{NMR}$ spectra of $\beta$-XO were close to those of GICR. Some of the signals split into two, indicating an inequivalence of the A- and B-rings. It had two high field signals at 47.6 and $47.9 \mathrm{ppm}$, showing the presence of a moiety other than the IDA moiety. The most striking feature of the spectra was the presence of an unusually low field signal around $210 \mathrm{ppm}$. The profile of the NMR spectra may suggest that $\beta$-XO has a triketone moiety formed by a ring condensation of the IDA moiety and formaldehyde as:

$$
-\mathrm{CH}_{2} \mathrm{~N}^{+} \mathrm{H}_{2}\left(\mathrm{CH}_{2} \mathrm{COOH}\right)_{2}+\mathrm{HCHO}
$$

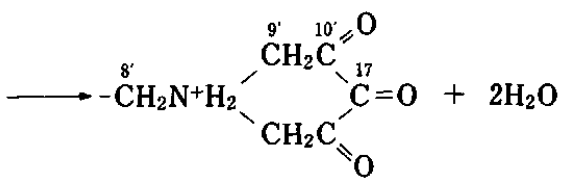

Then, the signal at $210 \mathrm{ppm}$ can be assigned to the central carbon $(C-17)$ of the triketone ${ }^{10}$ and the signals at 47.6 and $47.9 \mathrm{ppm}$ to aminomethylene $\left(\mathrm{C}-8^{\prime}\right)$ and carbonylmethylene (C-9') carbons of the moiety.

\section{Cation exchange column chromatography on SP-Sephadex under acidic condition}

As shown in Fig. 2, many colored materials were readily separated by the column method. The elution order of reactants and products of $\mathrm{XO}$ synthesis was IDA $<\beta$-XO $<\mathrm{GICR}<\mathrm{XO}<\mathrm{SXO}<\mathrm{CR}$, reflecting the difference in their mean charges $(1,0$ and -1$)$ in a $50 \mathrm{mM} \mathrm{HCl}$ eluent. The small charges under the acidic condition allowed for a speedy occurrence of the cation exchange chromatography. ${ }^{12}$

Purification of commercial dyes. Since commercial XO's still contain considerable amounts of SXO and other impurities ${ }^{11}$, it is preferable to purify them before use in order to obtain highly reliable results in spectrophotometry, or a sharp color change at the end point in chelatometry. A column chromatography on SP-Sephadex is quite suitable for this purpose; commercial dye was dissolved in a small amount of $50 \mathrm{mM} \mathrm{HCl}$, loaded on a column of $90-\mathrm{mm}$ length and was eluted with $50 \mathrm{mM}$ of $\mathrm{HCl}$. The separation of SXO and XO was achieved within $10 \mathrm{~min}$. In order to obtain pure $\mathrm{XO}$, top and tail parts of the XO band should be eliminated, the parts of which contained GICR and $\beta$-XO. The method was not, however, appropriate for isolating pure $\mathrm{XO}$, since it was difficult to remove $\mathrm{Cl}^{-}$and a sulfur-containing impurity (probably sulfoxypropyl sugars) from the dye. Methylthymol Blue and Methylxylenol Blue were also purified readily by using a column $220 \mathrm{~mm}$ in length with $10 \mathrm{mM} \mathrm{HCl}$ eluent. ${ }^{12}$

\section{References}

1. J. Körbl and P. Pribil, Chem. Ind.[London], 1957, 233.

2. K. L. Cheng, K. Ueno and T. Imamura, "Handbook of Organic Analytical Reagents", CRC Press, Boca Raton, Florida, 1982.

3. S. Nakada, T. Ito, M. Yamada and M. Fujimoto, Bull. Chem. Soc. Jpn., 54, 2913 (1981).

4. S. Murakami, K. Ogura and T. Yoshino, Bull. Chem. Soc. Jpn., 53, 2228 (1980); A. Yuchi, T. Okubo, H. Wada and G. Nakagawa, Anal. Sci., 3, 151 (1987).

5. M. Murakami, T. Yoshino and S. Harasawa, Talanta, 14, 1293 (1967).

6. S. Nakada, M. Yamada, T. Ito and M. Fujimoto, Bull. Chem. Soc. Jpn., 50, 1887 (1977); H. Sato, Y. Yokoyama and K. Momoki, Anal. Chim. Acta, 94, 217 (1977).

7. M. Yamada, I. Takiguchi, T. Suzuki, S. Nakada, T. Ito and M. Fujimoto, 29th Meeting of Coordination Chem. Jpn., Hamamatsu, 1979, 2 D10.

8. H. Nakayama, S. Tachiyashiki and E. Shimizu, Anal. Sci., 4, 595 (1988).

9. Each band shown in Fig. 2 was checked by a color reaction with $\mathrm{Fe}^{\text {III }}$. The GICR and $\beta$-XO were distinguished by a reaction with $\mathrm{Cu}^{\mathrm{II}}$ at $\mathrm{pH} 4.3$.

10. H. Kalinowski, S. Berger and S. Braun, " ${ }^{1 / 3} \mathrm{C}$ Nuclear Magnetic Resonance Spectroscopy", Wiley Interscience, New York, 1989.

11. XO of Dojindo Lab. contained XO(70\%), $\mathrm{SXO}(4.5 \%)$, GICR and $\beta-X O(1.5 \%)$, IDA(17\%; determined by DEAE Sephadex column chromatography and ninhydrin colorimetry $\left.{ }^{8}\right)$ and $\mathrm{Na}(7 \%, \mathrm{AAS})$.

12. S. Tachiyashiki, 38th Annual Meeting of the Chemical Society of Japan, Nagoya, 1978, 2 H21.

(Received May 31, 1989) (Accepted June 29, 1989) 